\title{
Gyrate Atrophy of the Choroid and Retina with Hyperornithinemia
}

\author{
CHARACTERIZATION OF MUTANT LIVER \\ L-ORNITHINE:2-OXOACID AMINOTRANSFERASE KINETICS
}

\author{
IlkKa SiPIlä and Olli Simell, Children's Hospital, University of Helsinki, 00290 \\ Helsinki, Finland \\ James J. O'DonNell, Department of Ophthalmology, University of California, \\ San Francisco, California 94143
}

\begin{abstract}
A B S T R A C T Deficient activity of L-ornithine:2-oxoacid aminotransferase is associated with gyrate atrophy of the choroid and retina with hyperornithinemia, an autosomal recessive disease leading to blindness. Liver tissue from two patients contained trace activity of the enzyme. The Michaelis $\left(K_{\mathrm{m}}\right)$ value of the mutant enzyme for ornithine was $200 \mathrm{mM}, 50$-fold higher than normal, but increasing the concentrations of $\alpha$-oxoglutarate and pyridoxal 5 '-phosphate to 10 times those giving maximal activity of the normal enzyme had no effect on the mutant enzyme. Substrate inhibition of the mutant could not be demonstrated at $1,000 \mathrm{mM}$ ornithine concentration, whereas ornithine concentrations above $70 \mathrm{mM}$ inhibited the normal enzyme. The data suggest that the abnormal L-ornithine:2-oxoacid aminotransferase in the two patients studied has an altered binding site for ornithine.
\end{abstract}

\section{INTRODUCTION}

Gyrate atrophy of the choroid and retina with hyperornithinemia $(\mathrm{GA})^{1}$ is an autosomal recessive disease characterized by night blindness and myopia by age 5-9 yr, posterior subcapsular cataracts, and progressive constriction of the visual fields often leading to blindness after 20-40 yr (1-3). The circular patchy atrophic lesions begin in the peripheral retina, enlarge, and coalesce, leaving only small central area of the posterior retina unaffected. In skeletal muscle, type II fibers

\footnotetext{
Address correspondence to Dr. Ilkka Sipilä at the University of Helsinki.

Received for publication 29 February 1981 and in revised form 16 March 1981.

${ }^{1}$ Abbreviations used in this paper: GA, gyrate atrophy; OAT, L-ornithine: 2-oxoacid aminotransferase; $V_{\max }$, maximum velocity of the enzyme reaction.
}

are atrophic and partly filled with tubular aggregates, and the mitochondria may be altered (4). Plasma ornithine is $10-20$ times higher than normal (5). In stimulated lymphocytes and cultured fibroblasts of the patients, the activity of L-ornithine:2-oxoacid aminotransferase (OAT) is usually unmeasurably low (6-11). In patients with GA, elevation of plasma ornithine after an intravenous arginine load is followed by a more rapid decrease in extracellular fluid ornithine than could be expected from urinary excretion and protein synthesis from arginine (12). This suggests that, in patients with GA, ornithine is degraded by some other mechanism, possibly by residual activity of the major catabolic enzyme, OAT. We report here that residual OAT activity with altered kinetics for ornithine is present in liver biopsies from two patients with GA.

\section{METHODS}

Preparation of liver homogenates. Percutaneous needle biopsies of the liver were performed in two patients with typical GA, a sister and brother, 32 and $28 \mathrm{yr}$ old. These tissues and normal control biopsies initially obtained for other reasons under laparotomy (patients aged 4-82 yr), were frozen immediately in liquid nitrogen, transported in dry ice, and stored at $-20^{\circ} \mathrm{C}$ until used for enzyme measurements. The liver samples were homogenized in 40 parts of $0.1 \mathrm{M}$ phos-

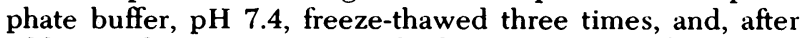
addition of Triton X-100 to a final concentration of $0.1 \%$ and standing for $10 \mathrm{~min}$ at room temperature, centrifuged at 3,000 rpm for $10 \mathrm{~min}$. The supernate was used for enzyme assays.

Enzyme assays. A micromodification of a method previously described (13) was used. For measurement of the enzyme kinetics the assay system contained $0.5-1,000 \mathrm{mM} \mathrm{L}$ ornithine, $3.75 \mathrm{mM} \alpha$-oxoglutarate, and $4 \mu \mathrm{g} / \mathrm{ml}$ pyridoxal 5 '-phosphate in a total volume of $25 \mu \mathrm{l} .40 \mu \mathrm{g}$ of GA and $1-10 \mu \mathrm{g}$ of control liver homogenate protein was used. The reaction was stopped after incubation for $60 \mathrm{~min}$ by adding $5 \mu \mathrm{l}$ of a mixture of $6 \mathrm{mg}$ ortho-amino-benzaldehyde in 
$500 \mu \mathrm{l}$ methanol and $500 \mu \mathrm{l}$ concentrated $\mathrm{HCl}$. The generation of dihydroquinazolinium from the product of the enzyme reaction, $\Delta^{1}$-pyrroline-5-carboxylic acid, was complete in $30 \mathrm{~min}$ at room temperature, after which precipitated protein was removed by centrifugation at $3,000 \mathrm{rpm}$ for $10 \mathrm{~min}$, and $10 \mu \mathrm{l}$ of the clear supernate was used for measurement of dihydroquinazolinium by high-pressure liquid chromatography with detection at $254 \mathrm{~nm}$. The integrated peak values were compared with an external standard of dihydroquinazolinium. The results represent means of duplicate determinations. Under the conditions used, the assays were linear with time and with added homogenate. In simultaneously run blanks, the stopping mixture was added before incubation, and they never showed any $\Delta^{1}$-pyrroline-5carboxylic acid formation.

Calculations. The Michaelis constant $\left(K_{\mathrm{m}}\right)$ and maximum velocity of the enzyme reaction $\left(V_{\max }\right)$ were computed after nonlinear curve fitting to $\mathrm{V}=\mathrm{V}_{\max }(\mathrm{S}) / K_{\mathrm{m}}+(\mathrm{S})$.

The patients with GA gave their informed consent, and the control liver samples were obtained with approval of the Children's Hospital's ethical committee.

\section{RESULTS}

When the samples from the patients with GA were assayed under conditions optimal for normal OAT, at $35 \mathrm{mM}$ L-ornithine and $3.75 \mathrm{mM} \alpha$-oxoglutarate concentrations, only trace amounts of $\Delta^{1}$-pyrroline-5-carboxylic acid were generated, but they were clearly detectable by high-performance liquid chromatography. This activity did not increase with increasing concentrations of $\alpha$-oxoglutarate and/or pyridoxal 5 'phosphate. 100-fold concentration of the latter inhibited the reaction. In the patients, Lineweaver-Burk plots of the OAT assays gave $K_{\mathrm{m}}$ values about 50 times that of the mean of controls. Apparent $V_{\max }$ values were in the mean four times higher in control homogenates and showed a large deviation (Fig. 1, Table I). Adding the mutant liver homogenate to the control sample did not decrease the activity of the normal enzyme. In the control homogenates, OAT activity showed substrate inhibition at ornithine concentrations $70 \mathrm{mM}(20$ times $K_{\mathrm{m}}$ ) (Fig. 1B), but in the patients with GA, no inhibition was seen at $1,000 \mathrm{mM}$ ornithine ( 5 times $K_{\mathrm{m}}$ ).

TABLE I

Kinetic Constants for Liver OAT

\begin{tabular}{lcc}
\hline & $K_{\mathrm{m}}$ & $V_{\max }$ \\
\hline \multirow{3}{*}{ Gyrate atrophy patients } & $m M$ & nmol/h/mg protein \\
& 206 & 79.9 \\
Controls & 213 & 86.4 \\
& 3.91 & 662 \\
& 4.98 & 312 \\
& 3.68 & 137 \\
Mean \pm SD in controls & 4.01 & 219 \\
\hline
\end{tabular}
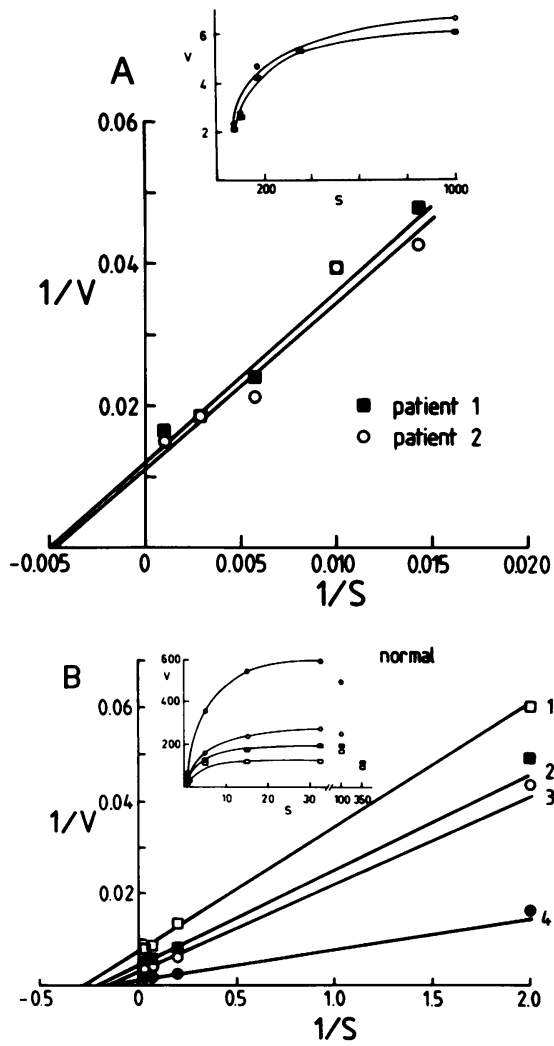

FIGURE 1 Lineweaver-Burk plots of the OAT activities in the liver of (A) two patients with gyrate atrophy and (B) four controls. The inset figures represent direct plots of reaction velocities against substrate concentrations showing the inhibition by the substrate at high substrate concentrations. $\mathrm{V}$, velocity in nanomoles product per hour per milligram protein. S, millimolar ornithine concentration. Note the different scales of Fig. 1A and $1 \mathrm{~B}$ necessitated by the very different kinetics.

The solubility of ornithine precluded assays at higher substrate concentrations, and kinetic studies with $\alpha$ oxoglutarate or pyridoxal 5 '-phosphate could not be performed because of the small amounts of sample available.

\section{DISCUSSION}

The residual OAT activity in liver homogenates of patients with GA had a $K_{\mathrm{m}}$ value for ornithine far above that in normal liver and far above the ornithine concentrations seen in physiological fluids. It was $\sim 250$-fold the mean plasma ornithine concentration of these two patients. The mean $K_{\mathrm{m}}$ in the control samples was $\sim 50$-fold the normal mean fasting plasma ornithine concentration. It is unlikely that any other enzyme but OAT could have been functioning in the assay, because the specific product of delta transamination 
of ornithine, $\Delta^{1}$-pyrroline-5-carboxylic acid, was measured (13). This unique delta transamination is not known to be catalyzed by other transaminating enzymes in mammals. However, final proof of the presence of OAT enzyme protein remains to be demonstrated with antiserum against human OAT.

Previous studies of OAT in patients with GA report only trace activities, not clearly differing from zero (6-10). The negligible OAT activity in most patients with GA may be due to the low ornithine concentrations (0.7-35 $\mathrm{mM}$ ) used in these assays which were performed on fibroblasts or stimulated lymphocytes. Such results may lead to the misinterpretation that patients with GA totally lack the OAT enzyme. An assay based on specific chemical measurement of the products and performed with metabolically active liver tissue is better suited for use in measurements of the kinetic constants. The fibroblasts of several patients $(11,14,15)$ show OAT activity at high pyridoxal 5 '-phosphate concentrations, indicating a kinetic mutation for pyridoxal $5^{\prime}$-phosphate. In our liver homogenates, elevation of pyridoxal 5 '-phosphate only inhibited the reaction. Increasing the $\alpha$-oxoglutarate concentration up to $37.5 \mathrm{mM}$ did not result in higher OAT activity. In our patients with GA, the mutation in OAT is probably in its site for ornithine binding.

These results are well in accordance with the observations in vivo. After an intravenous arginine load, plasma ornithine $t_{1 / 2}$ is $360 \mathrm{~min}$ in patients with GA compared with $97 \mathrm{~min}$ in controls (4). The fasting plasma concentrations in different Finnish patients with GA vary considerably (5). On the other hand, fasting ornithine concentrations taken at different times from the same individual are far more constant. These individual plasma ornithine levels could be determined by the individual $K_{\mathrm{m}}$ for OAT in the subject. This could be the reason for variable ornithine concentrations in GA, but the pathophysiologic importance of the severity of hyperornithinemia remains to be clarified.

\section{ACKNOWLEDGMENTS}

We thank Susan Hopkins and Julie Ansiello for their technical assistance.

This study was supported by National Institutes of Health grants EY-02706 and EY 02162, The Foundation for Pediatric Research, Finland, The Sigrid Jusélius Foundation, and the Association of the Finnish Life Insurance Companies.

\section{REFERENCES}

1. Cutler, C. W. 1895. Drei ungewöhnliche Fälle von Retino-Choroideal-Degeneration. Arch. Augenheilk. 30: $117-122$.

2. Takki, K. 1974. Gyrate atrophy of the choroid and retina associated with hyperornithinemia. Br.J. Ophthalmol. 58: 3-23.

3. Takki, K., and O. Simell. 1976. Gyrate atrophy of the choroid and retina with hyperornithinemia. In The Eye and Inborn Errors of Metabolism. D. Bergsma, A. J. Bron, and E. Cotlier, editors. Alan R. Liss, Inc., New York. 373384.

4. Sipilä, I., O. Simell, J. Rapola, K. Sainio, and L. Tuuteri. 1979. Gyrate atrophy of the choroid and retina with hyperornithinemia: tubular aggregates and type 2 muscle fiber atrophy in muscle. Neurology. 29: 996-1005.

5. Simell, O., and K. Takki. 1973. Raised plasma-ornithine and gyrate atrophy of the choroid and retina. Lancet. I: $1031-1033$.

6. O'Donnell, J. J., R. Sandman, and S. Martin. 1977. Deficient L-ornithine:2-oxoacid aminotransferase activity in cultured fibroblasts from a patient with gyrate atrophy of the retina. Biochem. Biophys. Res. Commun. 79: 396-399.

7. Trijbels, J. M. F., R. C. A. Sengers, J. A. J. M. Bakkeren, A. F. M. De Korte, and A. F. Deutman. 1977. LOrnithine-ketoacid-transaminase deficiency in cultured fibroblasts of a patient with hyperornithinemia and gyrate atrophy of the choroid and retina. Clin. Chim. Acta. 79: 371-377.

8. Valle, D., M. I. Kaiser-Kupfer, and L. A. Del Valle. 1978. Gyrate atrophy of the choroid and retina: deficiency of ornithine aminotransferase in transformed lymphocytes. Proc. Natl. Acad. Sci. U.S.A. 74: 5159-5161.

9. O'Donnell, J. J., R. P. Sandman, and S. R. Martin, 1978. Gyrate atrophy of the retina: inborn error of L-ornithine: 2-oxoacid aminotransferase. Science (Wash. D. C.). 200: $200-201$

10. Kennaway, N. G., R. G. Weleber, and N. R. M. Buist. 1977. Gyrate atrophy of the choroid and retina: deficient activity of ornithine ketoacid aminotransferase in cultured skin fibroblasts. N. Engl. J. Med. 297: 1180.

11. Shih, V. E., E. L. Berson, R. Mandell, and S. Y. Schmidt. 1977. Ornithine ketoacid transaminase deficiency in gyrate atrophy of the choroid. Am. J. Hum. Genet. 30: $174-176$.

12. Sipilä, I., O. Simell, and P. Arjomaa. 1980. Gyrate atrophy of the choroid and retina with hyperornithinemia. Deficient formation of guanidinoacetic acid from arginine. J. Clin. Invest. 66: 684-687.

13. O'Donnell, J. J., R. P. Sandman, and S. Martin. 1978. Assay of ornithine aminotransferase by high-performance liquid chromatography. Anal. Biochem. 90: 41-46.

14. Kennaway, N. G., R. G. Weleber, and N. R. M. Buist. 1980. Gyrate atrophy of the choroid and retina with hyperornithinemia: biochemical and histologic studies and response to vitamin $\mathrm{B}_{6}$. Am. J. Hum. Genet. 32: 529-541.

15. Hayasaka, S., Shiono, T., and Mizuno, K. 1980. Invest. Ophthalmol. 19(Suppl.): 185. 